\title{
La cura chamánica: \\ una interpretación psicosocial
}

\author{
Blanca Pelcastre-Villafuerte, Dra. en Psic. Soc.(1)
}

\section{Pelcastre-Villafuerte B. La cura chamánica: una interpretación psicosocial. Salud Publica Mex 1999;41:221-229.}

\section{Resumen}

Este trabajo constituye básicamente un análisis teórico de la cura chamánica en el que se propone la comunicación como base del proceso de curación, descrito este último a partir de los actos comunicativos, con énfasis en la interpretación de los elementos simbólicos. Se da cuenta de la dimensión en la cual se inscribe este proceso, la modalidad linguística que se emplea, el tipo de relación que se establece entre el/la chamán, el/la paciente y el grupo, la manera como se construye una realidad simbólica compartida, la visión de mundo del chamán y el efecto que tiene sobre las personas. Se toma el enfoque psico social como marco interpretativo y se propone una explicación en términos de la fundación de un acto comunicativo como escenario donde se construye una realidad simbólica, constituida por la cura pro piamente, a la que ingresa el paciente en cada sesión. Se analiza la visión mágica del chamanismo y su influencia sobre el proceso salud-enfermedad.

Palabras clave: realidad simbólica; comunicación; construcción social; cura; chamanismo

\section{Pelcastre-Villafuerte B.}

The shamanic cure:

A psychological interpretation.

Salud Publica Mex 1999;41:221-229.

\begin{abstract}
A bstract
The present paper is basically a theoretical analysis of the shamanic cure, which proposes communication as the basis of the healing process. This process is described as a communicative act focusing on the interpretation of symbolic elements. The context is the social dimension in which the process is inscribed, the linguistic mode employed, and the type of relationship established between the shaman, the patient and the people.We also recount the way in which a shared symbolic reality is built, and how the shaman's world view has important effects on people. The interpretative framework is the psychosocial focus and an explanation is offered in terms of the establishment of a communicative act as a scenario in which the symbolic reality is constructed, and in itself constitutes the cure into which the patient enters every session. The magical vision of shamanism is analyzed and its influence on the health-illness process.
\end{abstract}

Key words: symbolic reality; communication; social construction; cure; shamanism
E 1 mundo en que vivimos puede caracterizarse por su diversidad de expresiones culturales, las que se manifiestan en forma de costumbres, tradiciones, creencias y folklore en general; todas estas expresiones están conformadas por una variedad infinita de signos y símbolos a los cuales son sensibles las perso- nas, ya que con ellos se fundan los actos comunicativos sobre la base de un lenguaje compartido y se construye constantemente una realidad en un tiempo y un espacio determinados. ${ }^{1}$

La dimensión que aquí se retoma es la de la cultura y sus expresiones populares; por lo tanto, el pro-

(1) Departamento de Diseños y Modelos Alternativos de Atención, Dirección de Salud Comunitaria y Bienestar Social, Centro de Investigación en Sistemas de Salud, Instituto N acional de Salud Pública, México.

Fecha de recibido: 30 de abril de 1998 - Fecha de aprobado: 25 de marzo de 1999

Solicitud de sobretiros: Dra. Blanca Pelcastre Villafuerte, Centro de Investigación en Sistemas de Salud, Instituto N acional de Salud Pública. Av. Universidad 655, Col. Santa María A huacatitlán, 62508 Cuernavaca, Morelos, México. Correo electrónico: bpelcast@ insp3.insp.mx 
ceso descrito corresponde a una realidad simbólica del pensamiento mágico, que requiere del lenguaje para su interpretación.

Los protagonistas son los/as curanderos/as quienes, violando los criterios de la cientificidad positivista, conforman una realidad aparte donde el pensamiento y el sentimiento se conjugan para dar lugar a un evento que no es ni pensamiento ni sentimiento puro; esta cualidad diferencial confiere a los/as chamanes su propia especificidad, y su práctica tiene una fuerte influencia sobre las personas.

Las prácticas espirituales de los chamanes no son escasas o poco comunes; por el contrario, forman parte del complejo cultural cotidiano y están ampliamente extendidas. Todos los días acuden a los chamanes cientos de personas en demanda de atención, hacen largas filas y pasan horas enteras en espera de ser atendidas; esto sucede tanto en la Ciudad de México como en el resto de la República mexicana. Esta práctica es una parte importante de la riqueza cultural mexicana; sin embargo, cuando se habla de chamanes, no se alude a los asiátiacos, australianos, siberianos o mexicanos exclusivamente, sino que se hace referencia a todos ellos en su conjunto. Si bien es cierto que estas prácticas adquieren una especificidad en virtud de la región geográfica donde se ubican, es posible encontrar un proceso similar que subyace a todas ellas.

Los chamanes se alimentan de los pesares de las personas, de sus demandas y necesidades y, con todo ello, conforman su realidad, que responde a una visión particular del mundo y opera con una lógica específica. El efecto que pueden tener sobre la enfermedad encuentra su base en las creencias colectivas, lo que enfatiza la constitución de la salud como un proceso social.

\section{Pensamiento mágico}

La magia, entre otras formas sensibles del conocimiento, genera una visión de mundo muy especial. El pensamiento mágico juega con los símbolos; con ellos crea realidades simbólicas, puede expresarse pero no necesariamente lo hace con palabras; forma parte de la vida cotidiana y no tiene un modelo explicativo acabado a la manera de la racionalidad científica positivista. En este ámbito del saber, los fenómenos resultan inverificables, ya que los elementos constitutivos de los mismos son símbolos multívocos y, por tanto, el espectro de posibles explicaciones es muy amplio. Dada la diversidad de acontecimientos que se suceden en el ámbito social y su carácter no estático, se conforman realidades abiertas y complejas que coexisten con otras de carácter espiritual que apuntan al conocimiento del hombre y la mujer en su contexto social, de cara a la evolución de la humanidad más que a la evolución intelectual. $^{2}$

Resulta incoherente abordar esta dimensión mágica basada en la acción comunicativa, con un esquema de interpretación determinado y categorías de análisis preestablecidas; esta forma de proceder ha constituido, como lo señala Hughes, ${ }^{3}$ el fracaso de las ciencias sociales.

La magia se construye como forma de conocimiento ontológica y epistemológicamente diferenciable de la ciencia; sin embargo, ambas, ciencia y magia, se hallan mezcladas en el sujeto psicológico. Esto quiere decir que no hay una oposición en su manifestación individual, pues las explicaciones de una y otra índole pueden coexistir en los actores sociales sin que medie contradicción alguna.

En la vida cotidiana el pensamiento científico se mezcla con el pensamiento mágico y viceversa. Cuando un paciente se queja de dolor causado por una quemadura existe un daño físico, pero también es posible que haya sido víctima del mal de ojo producto de una riña; si llueve es porque un dios del cielo ha recompensado a los hombres y a las mujeres que cuidan la tierra, pero es igualmente cierto que esta precipitación pluvial bien puede explicarse por la condensación del vapor de agua que forma las nubes. Los ejemplos anteriores nos permiten apuntar, parafraseando a Kuhn, ${ }^{4}$ que la ciencia es también cuestión de fe, y en la vida cotidiana conviven la ciencia y la magia como parte de un mismo universo.

Todo pensamiento es comunicación; tanto la ciencia como la magia constituyen un tipo de pensamiento cuyo discurso se construye en términos diferentes, de tal manera que crean realidades simbólicas también diferentes, y ésta es una de las principales características de la comunicación: la construcción de ámbitos de realidad. Tal vez en el ámbito de los fenómenos llamados naturales, el significado de las cosas resulte inalterable, pero lo mismo puede llegar a ocurrir en la dimensión social, cuando los rituales se vuelven meros actos mecánicos, es decir, cuando se vacían de su significado original perdiendo su función primaria, y se convierten en repeticiones y meros convencionalismos. Entendido el pensamiento como forma de comunicación, un tipo no tiene por qué explicarse en los términos de otro; como lo expresa Price-Williams, ${ }^{5}$ "el esquema lógico no tiene por qué tener sentido para las propias creencias", en virtud de lo cual si es necesario podemos crear categorías nuevas de análisis que nos permitan entender realidades diferentes. La lógica de la razón irá siempre en la búsqueda de una idea para conectarla con otra, ${ }^{3}$ mientras que el pensamiento mágico se 
entenderá por medio del lenguaje afectivo y no buscará leyes generales que lo rijan ni esquemas conceptuales que lo conduzcan.

\section{El modelo teórico psicosocial}

El enfoque psicosocial que se retoma en el presente trabajo, rompe con la visión diádica de la estructura social individuo-sociedad, para ubicarse en el ámbito de la comunicación simbólica; su análisis se basa principalmente en métodos de tipo comprensivo y se ocupa de fenómenos de masas y multitudes, del lenguaje, de las influencias y los signos en general. Este enfoque concibe a la psicología social como "la ciencia de los fenómenos de la ideología (cogniciones y representaciones sociales) y de los fenómenos de comunicación". 6

El enfoque psicosocial propone un modelo tripolar en cuyos polos ubica al ego, al objeto y al sujeto social o alter, y establece entre ellos una interacción (figura 1).

El ego es un sujeto individual capaz de influir y ser influido por los demás individuos y de actuar sobre un objeto, que puede ser otro individuo o un grupo de ellos. La existencia del tercer elemento, el alter, es lo que permite la interpretación de la interacción ego-objeto, es lo que le otorga sentido a esta interacción, y puede concebirse como producto de la colectividad. En otras palabras, se alude a la intersubjetividad, a aquello que surge como producto de la interacción, del intercambio de significados, y que se constituye como una dimensión propia; puede concebirse también como ideología, representación social, lenguaje, símbolos, comunicación, todo aquello que permite entender al otro. ${ }^{1}$

Siguiendo el modelo psicosocial, la estructura social puede definirse como un sistema triangular simbólico cuyos vértices se muestran en la figura 2 .

Un símbolo es todo aquello que puede ser aprehendido por los participantes de la interacción, cuya creación y propiedad son de carácter social. ${ }^{7}$ El principal sistema simbólico en este contexto viene a ser el lenguaje.

Los símbolos representan la significación de las cosas $\mathrm{u}$ objetos [...] cuando [un] gesto representa la idea que hay detrás de él y provoca esa idea en el otro individuo, entonces tenemos un símbolo significante [...] Cuando el gesto llega a esa situación, se ha convertido en lo que llamamos "lenguaje".

Los significados son las representaciones de la experiencia o acontecimientos que refieren los símbolos, son de carácter subjetivo y, en esta medida, no son

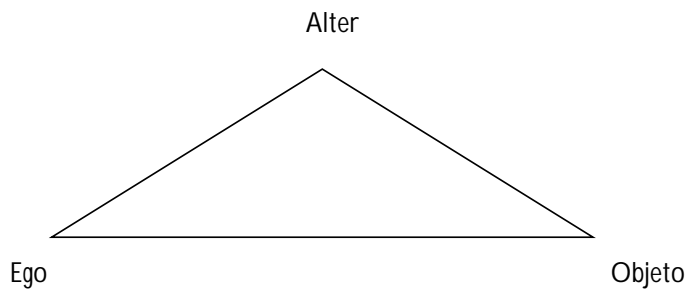

Figura 1. Modelo tripolar De LA APROXIMACIÓN PSICOSOCIAL

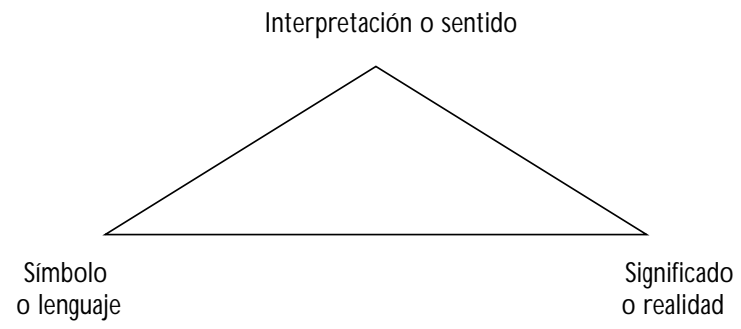

Figura 2. Estructura social a PARTIR DEL MOdELO TRIPOLAR

accesibles para todos los participantes; los significados son construcciones sociales. ${ }^{8}$

El tercer elemento, la interpretación, es la combinación de símbolos y significados, generados sobre la base de un acuerdo común, que otorgan sentido a las expresiones de la interacción. ${ }^{1}$ Estos tres elementos confluyen en un mismo tiempo y establecen entre ellos una relación dinámica, cuyo producto es la creación de una realidad simbólica.

En este sentido, la realidad, de aquí en adelante, será entendida como una realidad simbólica que se construye en la comunicación de los sujetos que intercambian símbolos y significados.

\section{Los actos comunicativos}

Nuestro ambiente es una atmósfera social simbólica y comunicativa, una realidad lingüística construida sobre la base de significados. El lenguaje es el instrumento por medio del cual se organiza la realidad en conceptos a los que se les atribuyen significados. ${ }^{9}$

En toda interacción social se crea una realidad intersubjetiva entre los participantes que prevalece aun en su ausencia; esta realidad se crea a partir del intercambio de signos y símbolos comunes y se mantiene sobre la base de un entendimiento o de significados 
compartidos, de tal forma que se funda un acto comunicativo.

Todo acto comunicativo está basado en el intercambio y la interpretación de símbolos y significados; ${ }^{1}$ un trazo sobre un papel, un color, un gesto, un vestido, una figura de madera, un espejo, un peine, un animal, todos ellos se constituyen como objetos simbólicos en la medida en que conllevan un significado implícito definido en la interacción.

Con el intercambio de símbolos y significados se va construyendo una realidad, que se presenta como una experiencia compartida y que es posible reconstruir con el lenguaje.

Este acto comunicativo del que se habla aquí no sólo implica la presencia de alguien que emite un mensaje con su correspondiente receptor, entre quienes media únicamente un código perfectamente descifrable, sino que va más allá de esto: se alimenta de pensamientos, sentimientos, imágenes, palabras, experiencias, y está constantemente fluyendo en la atmósfera social.

La comunicación puede darse tal como está expresada aquí, con palabras; sin embargo, también existe la comunicación no verbal que se trasmite por medio de expresiones faciales y corporales: una sonrisa, un guiño de ojo, una lágrima, un apretón de manos.

Mediante la comunicación no verbal, el individuo es capaz de revivir experiencias y, junto con la matriz conceptual, es decir, con las palabras propiamente dichas, integrar una representación perfectamente narrable. Ambas, la comunicación verbal y la no verbal, son elementos constitutivos de todo acto comunicativo; en una perfecta combinación otorgan sentido a los individuos, quienes crean y recrean con ello la realidad.

El significado no está en los objetos, sino que se construye en función del momento en que se utilizan éstos. Esta característica es la que ubica a los objetos como simbólicos, ya que son capaces de expresar un sentimiento, un deseo, una inquietud, un malestar, sin necesidad de recurrir a las palabras, o incluso lo pueden hacer mejor que éstas. Los significados que encierran los objetos simbólicos pueden ser tan concretos como un círculo rojo con una línea transversal sobre un cigarro, que prohíbe fumar, o tan abstractos como una paloma blanca que alude a la paz.

El lenguaje, las imágenes corporales, los gestos, la indumentaria, todos ellos se constituyen como sistemas simbólicos que propician la comunicación. En este sentido cualquier objeto puede ser un elemento simbólico, y sólo dentro de un contexto es susceptible de ser analizado.

\section{Chamanes y chamanismo}

La medicina tradicional puede ubicarse en dos dimensiones: en la del discurso teórico y en el espacio de la cultura; en este último es donde adquiere toda la gama de significaciones mágico-religiosas. En un intento por delimitar su ámbito, podemos distinguirla de otras prácticas, como la medicina popular o la doméstica, que se utilizan al interior de un grupo sin constituirse como saber formal y como un patrón de reproducción de saberes ancestrales, al contrario de lo que sucede con los terapeutas tradicionales; en esta categoría se engloban diversas especialidades, a saber: sobador, yerbero, huesero, chamán, pulsador, curandero. Esta clasificación se debe básicamente al tipo de práctica médica que llevan a cabo, así como a los sistemas de prevención o curación que se derivan de su especialidad. Según algunos autores, las parteras se ubican por separado debido a la exclusividad de su práctica. ${ }^{10}$

El chamanismo es una práctica que forma parte de esta estructura de la medicina tradicional y se define como la técnica del éxtasis, pues es justamente esta experiencia la que distingue al chamán de otros terapeutas. La experiencia extática es un estado del alma durante el cual ésta "abandona el cuerpo para emprender ascenciones al Cielo o descendimientos al Infierno" ${ }^{11}$ y se dice que en casi ninguna práctica religiosa se viven este tipo de experiencias.

Un chamán se inicia en la práctica después de tener una experiencia de alguna manera trágica, ${ }^{*}$ como por ejemplo ser alcanzado por un rayo, ${ }^{\ddagger}$ soñar con espíritus, sufrir ataques que conlleven un estado de inconsciencia del alma, convulsiones, enfermedades nerviosas, ataques epilépticos, tener una marcada preferencia por la soledad que lo lleva a mostrar cierto retraimiento. El elemento decisivo en la iniciación chamánica es el rito de la muerte y la resurección del futuro chamán; éste es el elemento extático fundamental que puede presentarse en las formas y/o sucesos extraordinarios ya mencionados.

En el cuadro I se resumen los métodos de reclutamiento y el tipo de instrucciones que pueden recibir los chamanes durante su iniciación, en la cual destaca la existencia de un núcleo fundamental cuyos elementos se encuentran estrechamente vinculados: experiencia-instrucción-reconocimiento del grupo.

\footnotetext{
* Esta experiencia se conoce con el nombre de "separación", pues se dice que el chamán experimenta un desprendimiento del alma. ₹ Esto explica el origen celeste de sus poderes.
} 


\section{Cuadro I \\ Métodos de RECLUTAMIENTO Y TIPO DE INSTRUCCIÓN CHAMÁNICOS}

$\begin{array}{ll}\text { Métodos de reclutamiento } & \text { - Por transmisión hereditaria } \\ & \text { - Por vocación espontánea } \\ & \text { - Por voluntad propia o del clan } \\ & \text { - De orden extático (sueños, trances, reve- } \\ & \text { laciones, etc.) } \\ & \text { - De orden tradicional (transmisión oral) }\end{array}$

Aunque representadas con distintos actos, las sesiones chamánicas de las diversas regiones conservan una misma esencia o significado original. En México, todavía podemos encontrar una gran cantidad de curanderos; como lo señala Grinberg-Zylberbaum:12 "se les encuentra en casi todo pueblo, comarca o ciudad, y forman una subcultura de complejidad y riqueza insospechadas".

La concepción de realidad de los chamanes considera la existencia de realidades alternativas; es decir, se trata de una realidad en la que coexisten, a la par de ésta, seres o espíritus con los cuales el chamán puede tener contacto y que le sirven de guía (espíritus aliados o protectores) o dificultan el trabajo curativo (espíritus del infierno), según el nivel en el que se les encuentre.

El ambiente en el que se llevan a cabo las prácticas recrea la realidad que los chamanes conciben: así, se observan altares adornados con flores e imágenes de santos, veladoras, estatuillas, incienso. La sesión es alumbrada con veladoras o velas únicamente, y todo se hace a media luz, lo cual favorece la cercanía física del paciente con el chamán; no hay grandes adornos y la atmósfera emana gran misticismo.

Los chamanes demuestran gran confianza en su cuerpo como instrumento de curación, elemento fundamental para el paciente, quien a su vez deposita en el chamán la fe en ser curado; cada movimiento y cada gesto es percibido simbólicamente y acogido con gran respeto, pues no hay cabida para la desconfianza.

A lo largo de una sesión el chamán describe, de forma tanto histriónica como oral, su experiencia extática. Desde el primer momento marca la pauta que permite al paciente y a sus familiares seguirlo en $\mathrm{su}$ viaje.

Las palabras que utiliza pueden no tener sentido para el observador incidental, pues expresan asombro, disgusto, resignación o insistencia ante una lucha que se libra en otro nivel, al cual no se tiene acceso.

Las lenguas mediante las cuales se expresan no son mera combinación fortuita de sonidos ininteligibles, sino que se articulan en forma por demás cohe- rente de acuerdo con la situación, pues si pensamos en una deidad, concebida como entidad superior al ser humano, dotada de poder inmesurable y como tal exaltada, no es posible dirigirse a ella con palabras comunes a las que todo mundo pueda tener acceso, sino que más bien debe tratarse de un lenguaje exclusivo. Su voz es, así, una melodía perfectamente armonizada, cuyos tonos se ven aumentados en los momentos cruciales de su viaje y disminuidos en los más tranquilos.

Se ha dicho que el entorno, delineado por una distribución característica de los espacios y constituido por los objetos materiales, los colores, la iluminación, cierto tipo de materiales, etc., dice mucho acerca de la modalidad sensorial de los individuos. ${ }^{13}$ Si pensamos en un lugar semioscuro, con objetos hechos generalmente con materiales naturales como piel, madera, hojas de mazorcas, con olor penetrante a incienso, paredes recubiertas de hierbas olorosas, con una mínima cantidad de muebles, pisos de lodo y arcilla y una temperatura agradable mantenida por un fuego permanente, como es la casa del chamán, ¿qué podemos pensar acerca de la modalidad sensorial por medio de la cual establece contacto? Todos estos elementos y arreglos del ambiente tendrán un impacto particular sobre el enfermo, en quien se producirá una sensación de bienestar, o bien, una molesta respuesta, dependiendo de sus expectativas, intereses, valores y experiencia personal.

El primer contacto que se establece entre el chamán y el paciente, se ve propiciado por todos estos elementos, se respira un ambiente de privacidad y, por tanto, las distancias conversacionales se acortan dando lugar a mensajes más personales en un tono de voz más suave. ${ }^{13}$

La estructura y el diseño del lugar hace posible que el chamán busque en el Cielo y el Infierno el alma del enfermo y que esto pueda tomarle un tiempo determinado. Generalmente junto a la casa del chamán y fuera de ella se encuentra un árbol o se tiene acceso a una escalera, por medio de los cuales intenta su ascenso al Cielo; su descenso al Infierno, en cambio, se ve limitado por el nivel del suelo.

A todos estos elementos habrá que añadir la propia imagen del chamán, quien asume que, para librar una lucha con entidades celestes o infernales, es necesario portar los elementos que le permitan hacerlo y que conforman en conjunto su indumentaria.

\section{Lógica del pensamiento mágico: lógica de la inmediatez}

El chamán mira a través de los ojos del alma, que no del cuerpo; habla, pero no son simples sonidos gutu- 
rales emanados de su garganta, sino que la que se escucha es una voz surgida del "más allá", de seres espirituales que se manifiestan por su conducto. Percibe dimensiones diferentes a las cuales puede ingresar casi en forma volitiva; canta, ríe, llora a su paso por los caminos del Cielo o del Infierno. El primer contacto corporal-visual con el paciente abre entre ambos un canal de comunicación no convencional y tal vez por ello más profundo. Son sus mundos privados los que entran en juego y todo lo que ello implica, sus pasiones, deseos y sentimientos.

En este proceso, el chamán se conduce de acuerdo con su cosmovisión particular: si puede ascender a los cielos o bajar a los infiernos es porque concibe una realidad dicotómica, pero además paralela; si puede recibir mensajes de seres suprahumanos es porque además estas realidades las ha poblado con esos seres; si puede hablar con los difuntos es porque éstos, al morir, sólo cambian de dimensión pero no dejan de existir; si el paciente que lo visita ha enfermado es porque su cuerpo es débil, no ha sabido conducirse por el buen camino o es depositario de una voluntad divina; si el chamán puede curarlo, es porque tiene el conocimiento, el poder y la fuerza espiritual que le han permitido haber sido elegido como instrumento de curación.

De esta manera nada es fortuito; no hay una clara separación entre vivos y muertos, y quizá la muerte sea extensión de la vida, o bien, sea la vida la que adquiera sentido por la posibilidad de muerte; no existe esa diferencia evolutiva entre animales y seres humanos, lo mismo un caballo que un hombre pueden ser sus aliados pues ambos tienen la fuerza y la capacidad para serlo.

Su magia no se opone a las prácticas médicas, sólo opera en diferentes niveles; los médicos trabajan con el cuerpo, mientras que para los chamanes lo más importante es el alma. Para ellos no hay límites espaciotemporales; ${ }^{*}$ estos límites son convencionales y son impuestos por la razón humana. Pueden lo mismo consultar a sus ancestros que vislumbrar el progreso de la enfermedad del paciente al mismo tiempo que comunicarlo en el aquí y el ahora. La realidad es atemporal, no existen las secuencias ni la cronología. Al final, el afecto y el pensamiento conviven y sirven para una misma causa: la sanación del enfermo.

\footnotetext{
* Se podría decir que adoptan el arte de la oscilación espacio-temporal que algunos autores como Vattimo ${ }^{14}$ reconocen como propio de la posmodernidad.
}

\section{Construcción de una realidad: la cura}

Esta lógica del chamán, que bien puede llamarse lógica de la inmediatez, construye una realidad que existe porque, una vez construida, es legitimada por los individuos quienes, sin necesidad de haber tenido una experiencia directa, cuentan con elementos que les permiten hacer flexible su lógica, trátese por ejemplo de experiencias indirectas, testimonios, etc., lo que hace factible su aceptación; ellos son quienes hacen posible que la realidad del chamán no se desvanezca y de esta manera pueda acceder el paciente.

El paciente puede provenir de lugares o realidades completamente diferentes cuyas reglas se ejercen de forma también diferente, cuyo lenguaje puede incluso tener otros usos y donde el pensamiento predomina sobre los afectos. No importa cómo llegue el paciente ni cuál haya sido su experiencia anterior; su primer contacto con el chamán representa la entrada a una realidad diferente, a una realidad aparte, lo que significa que debe ceder el paso al mundo de lo posible, de lo incomunicable, pues sólo aquí es factible que ambos, chamán y paciente, construyan juntos esa realidad que buscan: la cura.

Compartiendo signos y símbolos interpretan un significado común, atribuyen poder a los objetos y se dejan llevar por una nueva realidad que reconstruyen en cada encuentro.

Las palabras, el ambiente, los ritos corporales que acompañan al chamán, todos construyen una realidad que no es la del chamán ni la del paciente, sino la de ambos, cuyo sentido y significado tal vez termine ahí o quizá lo trascienda. Lo que ambos entiendan de su experiencia será producto de esta vivencia compartida, de lo que en ese momento signifique un silencio prolongado, de la manera como se use una estatuilla de madera, de la forma como se dirijan las palabras, de la disposición para escucharlas.

El prestigio y el consenso serán elementos que coadyuven en la creación y la conservación de dicha realidad. ${ }^{15}$

Evidentemente su entrada a este mundo provocará en el paciente una reacción emocional que lo hará susceptible a factores que en otro contexto tienen un efecto casi nulo y lo hará sensible a cualquier manifestación nueva o hasta entonces ignorada. Junto con el chamán, el paciente reinterpretará sus símbolos y significados y, en esta medida, será capaz de curarse.

Para explicar mejor este proceso se planteará en términos del modelo tripolar del alter, en donde en el lugar del símbolo estaría ubicado el lenguaje verbal y no verbal, mediante el cual se comunican el chamán 
y el paciente acompañados de esa gama infinita de gestos, de una serie de rituales, del ambiente y la atmósfera particulares que en esta práctica se crean.

El alter estaría bien representado por la comunidad en la que tiene lugar dicho proceso; toda comunidad tiene su propia historia, en la que se ha ido conformando todo un sistema de creencias puestas de manifiesto por medio de sus tradiciones, de sus costumbres, de su folklore; todo ello actúa como esquema de referencia y de interacción, en el cual tiene lugar el tercer elemento, constituido precisamente por el objeto de la comunicación, que en este caso es la cura chamánica (figura 3).

Este sistema funciona gracias a la interacción de todos sus elementos. El paciente, al entrar en contacto con el chamán, es capaz de dar un nuevo sentido a sus pesares; para él, estar enfermo significa ahora que hay alguien que entiende lo que le pasa, y no sólo eso, sino que conoce ese terreno y puede moverse en él, lo que le proporciona la posibilidad de ser curado. En otras palabras esto quiere decir que tiene lugar un proceso de resignificación; el paciente deja atrás las creencias con las que ingresa, la manera como entendía su enfermedad, para sustituirlas por una nueva visión de las cosas o por una explicación (sentido) en el caso de que su padecimiento no hubiera tenido ninguna, previa a la consulta. Esta explicación tendrá como característica el que pueda ser insertada en el sistema de creencias de la comunidad, es decir, tendrá que ser factible de acuerdo con los esquemas culturales del grupo, pues sólo así podrá ser preservada esta práctica.

\section{Observaciones finales}

Rescatando el interés que ha existido por el estudio de la medicina tradicional y su organización resalta, a manera de conclusión, la clasificación general de las entidades nosológicas que, a grandes rasgos y de acuerdo con su origen, se agrupan en: "naturales" y

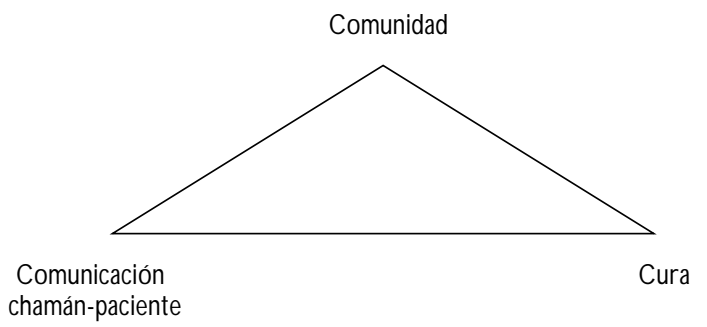

Figura 3. Cura chamánica a partir del modelo triPOLAR "sobrenaturales". El empacho y el susto son procesos que suelen ubicarse en ambas categorías; algunas tienen que ver más bien con el tipo de causa que las produce, como por ejemplo el mal viento del monte. Las enfermedades de origen sobrenatural se dividen en cuatro grupos: mal viento, mal de ojo, susto y hechizo.

El aire representa una de las principales etiologías de las entidades nosológicas; en la medicina tradicional indígena existen diversos padecimientos relacionados directa o indirectamente con este elemento. A manera de ejemplo está la pérdida de la som$b r a, \mathrm{y}$, a pesar de que su causa se relaciona más bien con el susto o la inseguridad vividos en un momento determinado, la consecuencia es un debilitamiento del cuerpo que permite que los malos aires se apoderen de la sombra. La pérdida de la sombra es un ejemplo de las llamadas enfermedades frías, es decir, las que se adquieren desde el exterior del cuerpo y cuya manifestación no es visible. ${ }^{16,17}$

Cabe señalar que esta importancia adjudicada a los elementos naturales proviene de la cosmovisión particular propia de los grupos donde se origina y que, a su vez, es motivo de la ubicación recurrente de la enfermedad en lo sobrenatural.

Entre las entidades nosológicas de filiación tradicional más extendidas se encuentran: el espanto, el mal de ojo, la pérdida del alma y el empacho. La etiología de muchos de estos padecimientos, así como su tratamiento, descansan sobre la concepción dicotómica frío-calor, donde la enfermedad se produce por el desequilibrio entre ambos elementos.

No es tarea sencilla tratar de entender todos estos cuadros sin un referente cultural, pues en todas estas entidades hay procedimientos rituales, conjuros, reglas específicas, donde la posibilidad de la cura no se sustenta en las creencias individuales del terapeuta tradicional y del paciente únicamente, sino que se debe a las tradiciones y creencias populares del grupo, el que permite interpretar lo que sucede entre aquéllos. En palabras de Lévi-Strauss: ${ }^{15}$

La eficacia de la magia implica [...] la creencia del hechicero en la eficacia de sus técnicas; luego la del enfermo que aquél cuida o de la víctima que persigue [...]; finalmente, la confianza y las exigencias de la opinión colectiva, que forman a cada instante una especie de campo de gravitación en cuyo seno se definen y se sitúan las relaciones entre el brujo y aquellos que él hechiza.

El lenguaje que subyace a todo pensamiento está cargado de imágenes; éstas a su vez están matizadas de emociones, de vivencias, de experiencias. Por ello, 
no puede haber pensamiento sin afectividad; son las palabras, pero también los gestos y movimientos, la indumentaria, el tono de voz, los colores, los olores, el tiempo y el espacio los que adquieren un significado a la luz del contexto en el que se circunscriben, lo que permite construir la realidad, producto de la interacción.

Es en la comunicación, en las palabras, donde reside precisamente la magia, donde se funden pensamiento y experiencia, donde la razón y el sentir son una misma cosa y coexisten para dar sentido al mundo del individuo. Al ser materializada, la magia se atribuye a un objeto o a una persona; de esta manera, quedan abiertas las posibilidades de que la capacidad depositada en los objetos se revierta en el propio individuo $y$, en esa medida, pueda acceder a esas otras realidades en las que sus propias capacidades potenciales se vuelvan parte activa.

Esta práctica es una pequeña muestra de las múltiples y variadas expresiones de la cultura popular; intentar caracterizar cualquiera de ellas resulta una tarea difícil, pues hacerlo nos remite irremediablemente a la descripción densa de un espacio de interacción particular que no se agota en la enumeración de acontecimientos. Así, toda pretensión correctiva y / o tipologizante se ubica fuera de todo intento por entender las expresiones populares. ${ }^{18}$

Para tratar de explicar por qué estas prácticas de medicina tradicional sobreviven a pesar de la vertiginosa corriente de la modernidad, debemos entenderlas como experiencias colectivas que tienen lugar en un mundo de vida compartido e histórico, ${ }^{19}$ manifestaciones que pueden tomar la forma de refranes, chistes, historias, leyendas, monumentos, que hacen las fiestas populares y las canciones, donde también vemos reflejada la espiritualidad de un pueblo, la mística de la cultura popular. ${ }^{20}$ Todo esto alimenta la memoria colectiva y otorga sentido a la existencia, son experiencias que se viven colectivamente y que se recuerdan de la misma forma. Así se conforman repertorios de saberes y prácticas que van enriqueciendo el legado cultural, al mismo tiempo que mantienen las tradiciones. Dichas creencias se encuentran históricamente situadas de manera que su aparición no es fortuita ni su desaparición prevenible; constituyen, en esta medida, condición de posibilidad de las acciones colectivas.

Ya desde Wundt se reconocía que las cuestiones espirituales resultan de la vida en común y no pueden ser explicadas en términos de conciencias individuales. El lenguaje, el arte, los mitos, las costumbres, la religión, la magia, son productos colectivos de los pueblos y se conforman en actos sociales en la medida en que en cada uno de ellos hay respuestas y, por tanto, interacciones. ${ }^{21}$

Estas expresiones mágicas de la cultura constituyen el repertorio distintivo de una comunidad -tal como lo señala Chaney ${ }^{22}$ al referirse a la aproximación vernácula de la cultura popular- y perviven porque consolidan de una forma importante la identidad de un pueblo. La identidad cultural es el espacio donde conviven rasgos de superficie y otros más profundos. En estos últimos se ubican la magia y la superstición, ${ }^{23}$ es lo que $\mathrm{McHale}^{24}$ llama retour de personnages, refiriéndose a ese espacio o zona intertextual donde coexisten diversos discursos, diferentes pensamientos y visiones de mundo, donde se mezclan ideas dando lugar a otras distintas, como la celebración de Navidad, donde convive la tradición religiosa con los fantasmas neoliberales del capitalismo como el consumismo; son las ficciones de nuestra vida colectiva, producto de lo que Canclini ${ }^{25-26, *}$ llama proceso de hibridización de las culturas, donde coexisten el pasado y el presente. Un buen ejemplo de ello es el fenómeno del nuevo curanderismo urbano, ${ }^{27}$ cuya práctica recupera elementos de la medicina popular y la práctica científica; estas fusiones o sincretismos, que ocurren con más frecuencia en los actos religiosos y manifestaciones tradicionales, son la condición de lo llamado "popular", y forman parte del movimiento continuo y del reacomodo de las prácticas sociales, que, sin embargo, generan identidades determinadas. Es un proceso de resignificación simbólica ${ }^{21}$ que se fortalece como espacios de resistencia al pensamiento y discursos hegemónicos, y que coadyuva a la autoctonía cultural ${ }^{28}$ de los pueblos; he aquí donde radica la verdadera fortaleza de las creencias y prácticas mágicas.

\footnotetext{
* De Grandis R. Incursiones en torno a la hibridación, una propuesta para discusión: de la mediación lingüística de Bajtín a la mediación simbólica de Canclini. Trabajo presentado en 1995 Meeting of the Latin American Studies Association; 1995 sept 28-30; Washington, D.C., EUA.
}

\section{Referencias}

1. Fernández P. La psicología so cial de la cultura cotidiana. En: Fernández $P$, comp. Psicología colectiva y cultura cotidiana. México, D.F.:U N AM-Facultad de Psicología (C uadernos de Psicología, Serie Psicosociología, núm. 1), 1989: 75-110

2. Mardones JM, U rsúa N . Filosofía de las ciencias humanas y sociales. 2a. edición. México, D.F.: Fontamara, 1988.

3. Hughes J. La filosofía de la investigación social. México, D.F.: Fondo de Cultura Económica (Breviarios, núm. 419), 1987. 
4. Kuhn TS. La estructura de las revoluciones científicas. 7a. edición. MéxiCo, D.F.: Fondo de Cultura Económica (Breviarios, núm. 213), 1986. 5.Price-W illiams D R. Por los senderos de la psicología intercultural. México, D.F.: Fondo de Cultura Económica (Breviarios, núm. 281), 1980.

6. Moscovici S. Prólogo e introducción: el campo de la psicología social. En: Moscovici S, comp. Psicología social I. Barcelona: Paidós, 1985: 1-6

7. Berger PL, Luckman T. La construcción social de la realidad. Buenos Aires:Amorrortu, 1991.

8. Mead GH. Espíritu, persona y sociedad. México, D.F.: Paidós, 1990.

9. Hall E. La dimensión oculta. 13a. edición. México, D.F.: Siglo Veintiuno Editores, 1989.

10. Herrero R, D urand JA, Rodríguez I,A guirre E. La sistematización en el estudio de la medicina tradicional mexicana. N ematihuani 1990;(8):17-22. 11. Eliade M. El chamanismo y las técnicas arcaicas del éxtasis. 2a. edición. México, D.F.: Fondo de Cultura Económica, 1986:23.

12. G rinberg-Zylberbaum J. Psicología autóctona mexicana. México, D.F.: Alpa Corral (Los chamanes de México), 1987; vol.1:12.

13. Knapp M. La comunicación no verbal. El cuerpo y el entorno. 2a. edición. España: Paidós (C omunicación, núm. 1), 1988.

14.Vattimo G. La sociedad transparente. Barcelona: Paidós/ICE de la Universidad Autónoma de Barcelona, 1994.

15. Lévi-Strauss C. El hechicero y su magia. En:Antropología estructural. Buenos Aires: Universitaria, 1977:125.

16. Castro R. La lógica de una de las creencias tradicionales en salud: eclipse y embarazo en 0 cuituco. Salud Publica Mex 1995;37(4):329-338.
17. Durand JA. Medicina tradicional mexicana: un saber en extensión. N ematihuani 1989;(3):21-30.

18. Joseph Y. El transeúnte y el espacio urbano. Barcelona: Gedisa, 1988.

19. Estrada M. Participación política. Actores colectivos. México, D.F.: Plaza y Valdés-U niversidad Iberoamericana, 1995.

20. A guilar MA, De Garay A, Hernández I comp. Simpatía por el rock. Industria, cultura y sociedad. México, D.F.: Universidad Autónoma Metropolitana, 1993.

21. Fernández P. La psicología colectiva un fin de siglo más tarde. Bogotá: Anthropos/El Colegio de Michoacán, 1994.

22. Chaney D. Fictions of collective life. Londres: Routledge, 1993.

23. Dieterich H. Emancipación e identidad de América Latina: 1492-1992.

En: Dieterich H, comp. N uestra América contra elV Centenario. 3a. edición. Bilbao:Txalaparta, 1990.

24. McH ale, B. Pöstmödernist Fictiön. 4a. reimpresión. Londres: Routledge, 1994.

25. García-C anclini N . Culturas híbridas: estrategias para entrar y salir de la modernidad. México, D.F.: Grijalbo, 1998.

26. G arcía-C anclini N . Las culturas populares en el capitalismo. 3a. edición. México, D.F.: N ueva Imagen, 1986.

27. Granero X. El curanderismo urbano: un fenómeno en expansión. Canelobre 1988; (11):19-26.

28. Markus, G. A society of culture: The constitution of modernity. En: Robinson G, Rundell J, eds. Rethinking imagination. Culture and creativity. Londres: Routledge, 1994. 